\title{
Role of osteopontin in bone remodeling and orthodontic tooth movement: a review
}

\author{
Amarjot Singh $^{1 *}$ (D), Gurveen Gill ${ }^{1,3}$, Harsimrat Kaur ${ }^{1,3}$, Mohamed Amhmed ${ }^{1,3}$ and Harpal Jakhu 2,4
}

\begin{abstract}
In this review, most of the known and postulated mechanisms of osteopontin (OPN) and its role in bone remodeling and orthodontic tooth movement are discussed based on available literature. OPN, a multifunctional protein, is considered crucial for bone remodeling, biomineralization, and periodontal remodeling during mechanical tension and stress (orthodontic tooth movement). It contributes to bone remodeling by promoting osteoclastogenesis and osteoclast activity through CD44- and avß3-mediated cell signaling. Further, it has a definitive role in bone remodeling by the formation of podosomes, osteoclast survival, and osteoclast motility. OPN has been shown to have a regulatory effect on hydroxyapatite crystal (HAP) growth and potently inhibits the mineralization of osteoblast cultures in a phosphate-dependent manner. Bone remodeling is vital for orthodontic tooth movement. Significant compressive and tensional forces on the periodontium induce the signaling pathways mediated by various osteogenic genes including OPN, bone sialoprotein, Osterix, and osteocalcin. The signaling pathways involved in the regulation of OPN and its effect on the periodontal tissues during orthodontic tooth movement are further discussed in this review. A limited number of studies have suggested the use of OPN as a biomarker to assess orthodontic treatment. Furthermore, the association of single nucleotide polymorphisms (SNPs) in OPN coding gene Spp1 with orthodontically induced root resorption remains largely unexplored. Accordingly, future research directions for OPN are outlined in this review.
\end{abstract}

Keywords: Osteopontin, Bone remodeling, Biomarkers, Root resorption, Orthodontic tooth movement

\section{Background}

Osteopontin (OPN) is a highly phosphorylated and glycosylated sialoprotein that is expressed by several cell types including osteoblasts, osteocytes, and odontoblasts. OPN belongs to the family of non-collagenous proteins known as SIBLING (small integrin-binding ligand, $N$-linked glycoprotein) [1]. In humans, OPN is encoded by Spp1 gene located on the long arm of chromosome 4 region 22 (4q1322.1). OPN is a prominent component of mineralized extracellular matrices of bones and teeth [2]. It has been found to be involved in a number of pathologic and physiological events including bone remodeling, biomineralization, wound healing, apoptosis, and tumor metastasis [2].

Bone remodeling is crucial for maintaining the normal skeletal structure as well as a key factor for orthodontic tooth movement. Orthodontic forces exert a significant

\footnotetext{
* Correspondence: amarjot.singh@mail.mcgill.ca

${ }^{1}$ Faculty of Dentistry, McGill University, Montreal, Quebec, Canada Full list of author information is available at the end of the article
}

amount of compressive [3-9] and tensional [7, 10-13] forces on the periodontium to induce the signaling pathways mediated by various osteogenic genes including OPN, bone sialoprotein, Osterix, and osteocalcin. The signaling pathways and response of the periodontium differ on both tension and compression sides; however, OPN is ubiquitously expressed in bone remodeling on both sides [13].

In this review, our focus will be on the events controlled by OPN in bone remodeling and orthodontic tooth movement. In addition, the prospects of OPN in accelerating tooth movement and root resorption and as a biomarker will be outlined. In our knowledge, no study till date has reviewed the mechanisms involved in OPN-mediated bone remodeling during orthodontic tooth movement.

\section{OPN structure and its expression and regulation}

OPN is multifunctional protein owing to its structure. OPN molecule comprises unique conserved regions 
which involve (RG)-binding domain, serine/threonine phosphorylation site, two heparin-binding sites, one thrombin cleavage site, and a putative calciumbinding site [14]. The cell interacting domains include arginine-glycine-aspartic acid (RGD) cell-binding sequence and serine-valine-valine-tyrosine-glutamateleucine-arginine (SVVYGLR) motif [15]. The cleavage sites include thrombin and matrix metalloprotinase's (MMP's) cleavage sites [14]. In response to cleavage by thrombin, SVVYGLR site is revealed and leads to the formation of two segments: N-terminal fragment and C-terminal fragment (Fig. 1). The pro-inflammatory $\mathrm{N}$-terminal segment includes two integrin-binding sites: RGD and SVVYGLR motifs [15]. However, the C-terminal fragment is devoid of an integrin-binding site. MMP's cleave both fragments by binding to MMP's cleavage sites: cleaving $\mathrm{N}$-terminal fragment leads to inactivation of integrin-binding domain of SVVYGLR motifs [15].

The expression of OPN is regulated by a large number of cytokines, hormones, and growth factors, which affects gene transcription, translation, and post-translational modifications (Table 1) [16]. Also, expression of OPN increases in response to mechanical stress [17-19]. Therefore, it is a critical factor in regulating bone remodeling in responses to mechanical stimuli.

\section{OPN in bone remodeling}

OPN is considered to play important role in bone formation and resorption [20-22]. It is highly concentrated at cement lines where pre-existing and newly formed bone meet and at bone surfaces interfacing with cells called as laminae limitantes [23]. There are various levels of mediation of OPN in bone remodeling. For example, OPN is demonstrated to have chemotactic activity [24] on the precursor of osteoclasts, at a concentration from $10 \mathrm{nM}$ to $1 \mu \mathrm{M}$ [17]. Also, OPN-dependent intracellular signaling is seen in sealing zone formation in osteoclastic resorption (Fig. 2a, b). Broadly, various authors described the following pathways in OPN-mediated bone remodeling.

\section{Integrin av $\beta 3$-mediated signaling}

OPN binds to several integrins including $\alpha \mathrm{v} \beta 3, \alpha \mathrm{v} \beta 5$, $\alpha v \beta 1, \alpha 4 \beta 1, \alpha 5$, and $\alpha 9 \beta 1$. OPN binding to $\alpha v \beta 3$ is crucial for major post-receptor signal responses, which involves regulation of osteoclastic activity and activation of osteoprotegerin expression [24, 25]. Further, OPN binding to integrin $\alpha v \beta 3$ plays a major role in the formation of sealing zone in osteoclast activity. OPN- $\alpha v \beta 3$ binding on the surface of osteoclasts induces integrin clustering and leads to intracellular signaling by phosphorylation of protein tyrosine kinase 2 (PYK2) $[25,26]$ that facilitate binding of proto-oncogene tyrosine-protein kinase $(\mathrm{Src})$ via its SH2 domain. This Src-PYK2 binding leads to further phosphorylation of PYK2 at other sites which amplifies the signals activating cellular functions including cell adhesion such as sealing zone formation (Fig. 2b) [25, 26].

It has also been suggested that integrin $\alpha v \beta 3$, Src, and Fms (the receptor for M-CSF) stimulate Spleen tyrosine kinase (Syk) which further mediates GTP loading on Rac1 via Vav3 in osteoclasts [27]. GTP loading on Rac 1 drives cytoskeletal remodeling leading to bone resorption. Certain proteins including Wiskott-Aldrich syndrome protein (WASP) and gelsolin are also regulated by integrin $\alpha v \beta 3$. This process is vital for the podosome formation on osteoclasts [27].

In addition, OPN binding to integrin $\alpha v \beta 3$ has been suggested to modulate intracellular $\mathrm{Ca}^{2+}$ through stimulation of $\mathrm{Ca}^{2+}$ release from intracellular compartments and regulating extracellular calcium influx via $\mathrm{Ca}^{2+}$-ATPase pump $[28,29]$. The induction of cytosolic $\mathrm{Ca}^{2+}$ further modulates osteoclast activity by translocation of transcription factor NFATc1 (nuclear factor of activated $\mathrm{T}$ cells, cytoplasmic 1) through the $\mathrm{Ca}^{2+}$-NFAT pathway (Fig. 2b) [30, 31]. This NFATc1 has been shown to be imperative for osteoclastogenesis [32-34], leading to the increased resorptive activity of mature osteoclasts [30,31].

\section{CD44-associated cell signaling}

Osteoclasts deficient in OPN show no migratory activity and do not resorb bone [35]. It has been demonstrated

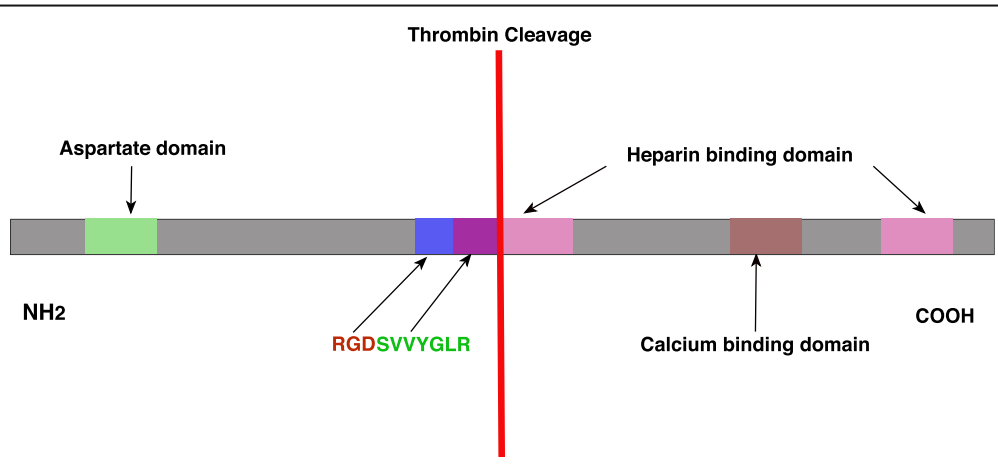

Fig. 1 A schematic representation of osteopontin structure and thrombin cleavage site. RGD (arginine-glycine-aspartic acid) and SWYGLR (serine-valine-valine-tyrosine-glutamate-leucine-arginine) binding domains are indicated 
Table 1 Factors affecting the expression and regulation of osteopontin

\begin{tabular}{|c|c|}
\hline Expression and upregulation of OPN & Downregulation of OPN \\
\hline Transcription factors-Runx2 and Osterix [68] & cGMP-dependent protein kinase [2] \\
\hline Inorganic phosphate [69] & Bisphosphonates [2] \\
\hline $\begin{array}{l}\text { Systematic conditions-hypophosphatemia, hypocalcemia [2] } \\
\text { Hormones-glucocorticoids, [70] } \\
\text { 1,25-dihydroxyvitamin D3, [70] parathyroid hormone [14] }\end{array}$ & ERK inhibitor \\
\hline \multicolumn{2}{|l|}{ Vitamins_retinoic acid [70] } \\
\hline \multicolumn{2}{|l|}{ Inflammatory mediators - TNFa, IL-1 $\beta$, TGF $\beta$ [14] } \\
\hline Mechanical stress & \\
\hline
\end{tabular}

that OPN-deficient osteoclasts, when treated with exogenous OPN, result in an enhanced CD44 expression [36]. CD44-induced cell signaling enhances osteoclast motility [35], which partially restores bone resorption, by activation of $\alpha v \beta 3$ integrin [36, 37]. OPN stimulate osteoclast migration through $\alpha v \beta 3$ and CD44-mediated cell signaling, which further increases CD44 expression on osteoclasts [35, 36]. Addition of exogenous OPN partially restores the resorptive activity of osteoclasts, which indicates autocrine OPN is important to osteoclast activity [36]. However, exogenously added OPN does not have access to OPN secreted by osteoclasts, which are present in resorption lacuna [36]. The intracellular form of OPN (iOPN), an integral component of the CD44-ERM complex, is seen to be involved in migrating fibroblasts, macrophages, osteoclasts, and metastatic breast cancer lines [2, 38]. A hypothetical pathway was described in which iOPN with components of CD44-ERM is involved in cell migration [2, 38]. Further, it has been demonstrated that overexpression of phosphatase and tensin homolog (PTEN) restricts PI3-kinase signaling, suppresses receptor activator of nuclear kappa-B ligand (RANKL) and OPN-induced Akt activation, and ultimately results in the downregulation of osteoclast differentiation and cell motility [39].

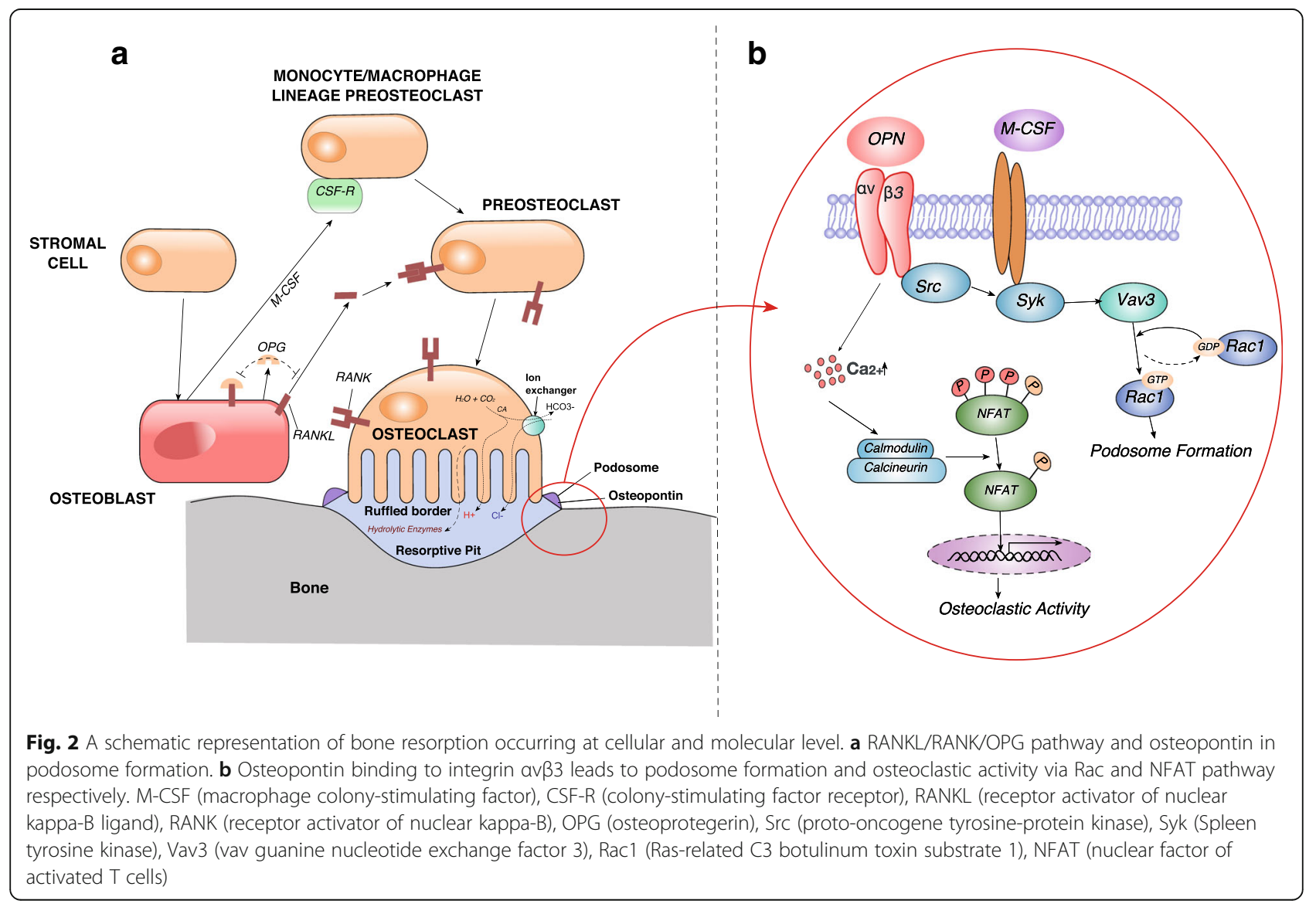




\section{Inhibition of mineral deposition}

The bone matrix consists of the inorganic component, hydroxyapatite (HA), and organic component, proteins and proteoglycans [2]. OPN protein along with other SIBLING proteins contain acidic, serine-, and aspartate-rich motif (ASARM) which are the potential phosphorylation sites [1]. Phosphorylated OPN inhibits mineralization via phosphate residues [40]. Contrary to it, OPN dephosphorylation by tissue-non-specific alkaline phosphatase (TNAP) prevents much of its mineral binding and crystal growth activity [40]. Both pyrophosphate (PPi) and OPN contains highly negative charge phosphate residues which inhibit mineralization after binding to HA crystals [40]. It has been shown that peptide phosphorylated MEPE ASARM (pASARM) has a greater affinity for HA than nonphosphorylated ASARM (npASARM). OPN can act independently of PPi as well as a mediator of PPi effects. High levels of extracellular PPi lead to increased OPN expression and secretion by osteoblasts [40].

Pyrophosphate prevents mineralization by three proposed mechanisms. Firstly, there is direct binding of PPi to growing HA crystals. Secondly, there is the induction of OPN expression by osteoblasts through MAPK pathway, enabling the coordinated action of both PPi and OPN [40]. Thirdly, there is a feedback mechanism in which Pi/PPi ratio inhibits TNAP activity [40]. Even though OPN is considered as mineralization inhibitor, it has been shown that OPN can serve as an agent for intra-fibrillar mineralization in collagen [41], thus pointing towards the multifunctional role of OPN.

\section{Potential role of OPN in orthodontic tooth movement}

Various knockout studies have demonstrated that bone remodeling is impaired in OPN-deficient mice [42] in response to mechanical stress $[8,43,44]$. An animal study [44], by Walker et al., has revealed that OPN is required for osteoclast recruitment through RANKL expression in unloaded mechanical stress (unopposed molar model). Further, it has been suggested that OPN mediates osteoclast activity, RANKL expression, and bone resorption at unloaded alveolar bone walls using a PI3K- and ERK-dependent mechanism [44]. No distal drifting was reported in the OPN-deficient mice [44].

In the initial stages of orthodontic tooth movement, OPN is observed in the osteocytes [13]. A study [17] suggested the change in the number of OPN mRNA expressing osteocytes on the pressure side after $48 \mathrm{~h}$ of mechanical stress and reached a maximum value at $72 \mathrm{~h}$ [8], coinciding with bone resorption. However, in the later stages of OTM, OPN is ubiquitously expressed in PDL cells, osteoclasts, cementocytes, cementoblasts, and osteoblasts as well as the cement line of alveolar bone and cementum $[13,45,46]$. The potential signaling pathways involved in the OPN regulation during the orthodontic tooth movement on compression as well as on tension side are summarized in Fig. 3.

\section{OPN and RANKL regulation on compression side}

Wongkhantee and coworkers first studied the OPN expression in human periodontal ligament cell (HPDL) via Rho kinase pathway (Fig. 3) [4] and analyzed that stress-induced ATP activates Rho kinase pathway via the purinoreceptor 1 (P2Y1) receptor [5]. They proposed that RANKL upregulation during mechanical compression may be further induced via activation of $N F K B$ pathway-mediated release of cyclooxygenase and prostaglandin E2 (PGE2) production [3]. Later, various research groups analyzed the Rho kinase-mediated OPN induction. Hong et al. reported that OPN induction during compression is mediated by RhoA-controlled focal adhesion kinase (FAK) and extracellular signal-regulated kinase (ERK) pathways in human periodontal ligament fibroblasts (Fig. 3). ERK further phosphorylates ETS domain-containing protein (Elk-1) which results in the transcription of OPN [47].

OPN and RANKL collectively work to induce the bone resorption in response to compressive forces (Fig. 3). Osteoblasts and stromal stem cells express receptor activator RANKL which binds to its receptor, receptor activator of nuclear kappa-B (RANK), on the surface of osteoclasts and their precursors. This regulates the differentiation of precursors into multinucleated osteoclasts $[48,49]$. In addition, a study by Walker and coworkers suggested that increased OPN expression enhances RANKL expression via extracellular matrix signaling pathway in unloaded distal drift [44]. Nevertheless, no study has assessed the influence of OPN expression on RANKL in mechanically stressed condition viz. orthodontic tooth movement and need further investigation.

\section{OPN regulation on tension side}

$\mathrm{Su}$ et al. first reported the expression of a gap junction alpha-1 protein, connexin 43 , on tension side during orthodontic tooth movement in rat periodontal ligament cells [10]. Later, Shengnan et al. confirmed the involvement of connexin 43 and ERK in tension-induced signal transduction human periodontal ligament fibroblasts (Fig. 3) [7]. It was reported that ERK further induces the transcription of osteogenic proteins, runt-related transcription factor 2 (RUNX2), osteoprotegerin (OPG), and Osterix [7]. In a recent study, the upregulation of OPN along with alkaline phosphatase, collagen I, osteocalcin, and bone sialoprotein was reported via ERK and p38 MAPK-mediated pathway during orthodontic tooth movement in response to tension stress [11]. Thus, both ERK and p38 were proposed to be significantly involved 


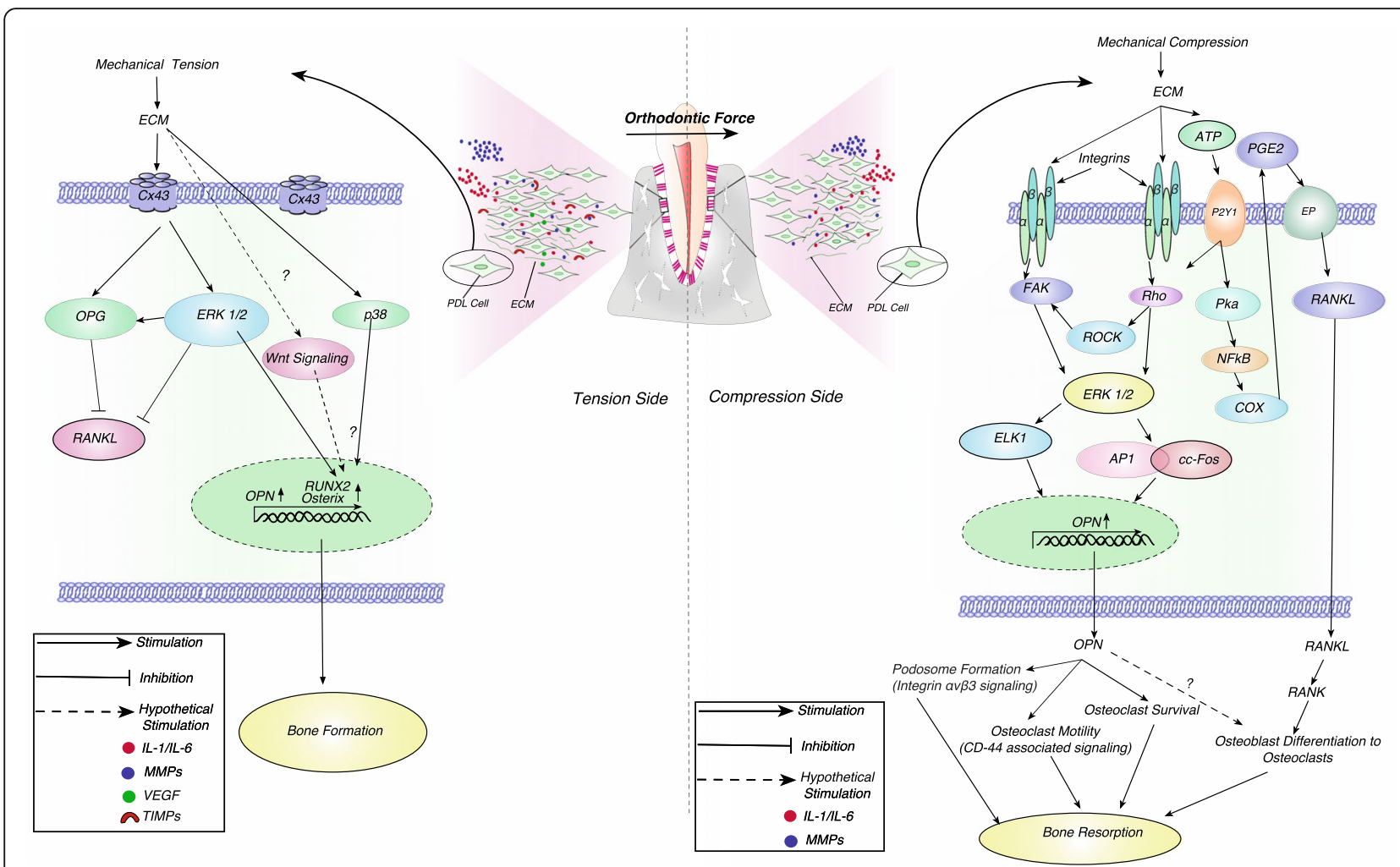

Fig. 3 A schematic representation of osteopontin regulation and osteopontin-mediated periodontal remodeling during orthodontic tooth movement at tension side and compression side. ECM (extra-cellular matrix), PDL (periodontal ligament), Cx43 (connexin 43), ERK1/2 (extra-cellular signal-regulated kinase 1,2), RUNX2 (runt-related transcription factor 2), IL-1/IL-8 (interleukin 1/8), MMP's (matrix metalloproteinases), VEGF (vascular endothelial growth factor), TIMP's (tissue inhibitors of metalloproteinases), ATP (adenosine triphosphate), PGE2 (prostaglandin E2), EP, RANKL (receptor activator of nuclear kappa-B ligand), RANK (receptor activator of nuclear kappa-B), OPG (osteoprotegerin), P2Y1 (purinoreceptor 1), Pka (protein kinase A), NFkB (nuclear factor kappa B), COX (cyclooxygenase), ROCK (Rho-associated protein kinase), FAK (focal adhesion kinase), ELK1 (ETS domain containing protein), AP1 (activator protein 1)

in periodontal remodeling during orthodontic tooth movement [11].

Wnt/ $\beta$ catenin pathway has been shown to be significantly involved in the matrix formation in response to mechanical strain [50-54]. Whether this pathway is involved in the tension forces created during the orthodontic tooth movement is not yet known. Thus, we hypothesize that strain-induced transduction of $\mathrm{Wnt} / \beta$ catenin could be involved in the upregulation of osteogenic proteins including Osterix and OPN (Fig. 3).

\section{OPN-mediated tooth root resorption and repair}

Root resorption is one of the side effects of the orthodontic treatment and is the result of activity of odontoclasts [45]. A mice study showed odontoclast expressing OPN mRNA appeared on the surface of the active root resorption 5 days after orthodontic movement [45]. Similarly, Chung et al. demonstrated that OPN deficiency has much more enhanced effect on the decrease in the odontoclastic activity than osteoclastic activity [43]. They proposed that abundance of inflammatory regulators in the alveolar bone might overwhelm the deficiency of OPN, thereby having little effect on the bone resorption [43]. In contrast to the alveolar bone, cementum and root surface of the tooth is deficient in the inflammatory mediators, thereby enhanced odontoclastic activity may be the one reason in OPN-deficient mice [43]. Thus, OPN is a crucial factor in force-induced root resorption of tooth [43]. Jimenez-Pellegrin et al. demonstrated that OPN plays a key role in both cementum resorption and repair after orthodontic rotation movement [55].

On the other hand, the role of OPN in cementogenesis followed by mechanical injury was also studied in the epithelial cell rests of Malassez (ECRM) [56, 57]. It has been suggested that ECRM express various osteogenic genes including OPG and OPN [56]. Also, immunohistochemical characteristics of ECRM suggested that it may be significantly involved in the secretion of matrix proteins including OPN to further induce cementum repair followed by mechanical injury [57].

Various research groups studied the single nucleotide polymorphisms (SNPs) in the OPN coding gene Spp1 and its effect on the tooth root resorption [58-60]. Iglesias-Linares and coworkers first reported that OPN 
gene SNPs (rs9138, rs11730582) are involved in the susceptibility of external root resorption in patients undergoing orthodontic treatment [58]. However, in another study, OPN gene SNPs and its effect on external apical root resorption (EARR) were not confirmed in Czech children [60]. However, the association between individual variability in purinoreceptor (P2X7) and EARR was suggested to be an important factor in the etiopathogenesis of EARR [60]. Iglesias-Linares et al. later implicated the Spp1 gene SNPs to assess the orthodontically induced external apical root resorption (OIEARR) in patients with removable appliances versus fixed appliances [59]. No any predisposition to OIEARR was reported with response to fixed and removable appliances [59].

\section{Future directions}

Since OPN is ubiquitously expressed in periodontal remodeling during orthodontic tooth movement, various research groups have implicated OPN as a biomarker to assess the tissue response with respect to orthodontic treatment [61]. The samples were collected from GCF and a protein levels were assessed [61-65]. DNA methylation biomarkers of Spp1 gene and other osteogenic genes may also be helpful to understand the individual variability in response to orthodontic treatment [66]. Thus, a more tailored and personalized approach [66] can be drawn to treat patients with an increased predisposition to OIEARR via targeting the epigenetic mechanisms. Similarly, micro RNAs targeting the osteogenic genes can be assessed.

Alveolar decortication has been shown to induce the rate of tooth movement via the coupled mechanism of bone resorption and formation in early stages of orthodontic tooth movement [67]. The underlying biomarkers (OPN, osteocalcin, bone sialoprotein) demonstrated increased anabolic activity. Whether the orthodontic tooth movement can be accelerated via targeting the underlying signaling pathways warrants further investigation.

\section{Conclusions}

OPN has a definitive role in the formation of podosomes, osteoclast survival, and osteoclast motility. Various OPN-mediated signaling pathways involved in the periodontal remodeling facilitate orthodontic tooth movement. There is a need to pharmacologically target these signaling pathways in order to decrease the side effects of orthodontic treatment including tooth root resorption in patients with an increased predisposition to OIEARR. In addition, the application of OPN biomarkers should be assessed and compared at proteomic, genomic, and epigenomic levels in order to gain a more tailored orthodontic approach. Nonetheless, there is dire need of validated studies to further translate the relevance of OPN in orthodontic treatment.

\section{Abbreviations}

AP1: Activator protein 1; ATP: Adenosine triphosphate; COX: Cyclooxygenase; CSF-R: Colony-stimulating factor receptor; Cx43: Connexin 43; ECM: Extracellular matrix; ELK1: ETS domain containing protein; EP, P2Y1: Purinoreceptor 1; ERK1/2: Extracellular signal-regulated kinase 1,2; FAK: Focal adhesion kinase; IL-1/IL-8: Interleukin 1/8; M-CSF: Macrophage colony-stimulating factor; MMP's: Matrix metalloproteinases; NFAT: Nuclear factor of activated T cells; NFkB: Nuclear factor kappa B;

OPG: Osteoprotegerin; PDL: Periodontal ligament; PGE2: Prostaglandin E2; Pka: Protein kinase A; Rac1: Ras-related C3 botulinum toxin substrate 1; RANK: Receptor activator of nuclear kappa-B; RANKL: Receptor activator of nuclear kappa-B ligand; RGD: Arginine-glycine-aspartic acid; ROCK: Rhoassociated protein kinase; RUNX2: Runt related transcription factor 2; Src: Proto-oncogene tyrosine-protein kinase; SWYGLR: Serine-valine-valinetyrosine-glutamate-leucine-arginine; Syk: Spleen tyrosine kinase; TIMP's: Tissue inhibitors of metalloproteinases; Vav3: Vav guanine nucleotide exchange factor 3; VEGF: Vascular endothelial growth factor

\section{Authors' contributions}

AS made a substantial contribution to the conception, design, and revision of the manuscript. GG, HK, MA, and $\mathrm{HJ}$ made contributions in the revision of the manuscript. AS and HK designed the figures. All authors read and approved the final manuscript.

Ethics approval and consent to participate

Ethical approval was not required.

\section{Competing interests}

The authors declare that they have no competing interests.

\section{Publisher's Note}

Springer Nature remains neutral with regard to jurisdictional claims in published maps and institutional affiliations.

\section{Author details}

${ }^{1}$ Faculty of Dentistry, McGill University, Montreal, Quebec, Canada. 2Department of Endodontics, Government Dental College, Amritsar, Punjab, India. ${ }^{3}$ Lady Davis Institute, Jewish General Hospital, Montreal, Quebec, Canada. ${ }^{4}$ Sandalwood Smiles, Private Dental Practice, Brampton, Ontario, Canada.

Received: 27 February 2018 Accepted: 24 May 2018

Published online: 25 June 2018

\section{References}

1. Staines KA, MacRae VE, Farquharson C. The importance of the SIBLING family of proteins on skeletal mineralisation and bone remodelling. J Endocrinol. 2012;214:241-55.

2. Sodek J, Ganss B, McKee MD. Osteopontin. Crit Rev Oral Biol Med. 2000;11:279-303.

3. Luckprom P, Wongkhantee $S$, Yongchaitrakul T, Pavasant P. Adenosine triphosphate stimulates RANKL expression through P2Y 1 receptor-cyclooxygenase-dependent pathway in human periodontal ligament cells. J Periodontal Res. 2010;45:404-11.

4. Wongkhantee $S$, Yongchaitrakul T, Pavasant P. Mechanical stress induces osteopontin expression in human periodontal ligament cells through rho kinase. J Periodontol. 2007;78:1113-9.

5. Wongkhantee $S$, Yongchaitrakul $T$, Pavasant $P$. Mechanical stress induces osteopontin via ATP/P2Y1 in periodontal cells. J Dent Res. 2008;87:564-8.

6. Luckprom P, Kanjanamekanant K, Pavasant P. Role of connexin43 hemichannels in mechanical stress-induced ATP release in human periodontal ligament cells. J Periodontal Res. 2011;46:607-15.

7. Li S, Zhang H, Li S, Yang Y, Huo B, Zhang D. Connexin 43 and ERK regulate tension-induced signal transduction in human periodontal ligament fibroblasts. J Orthop Res. 2015;33:1008-14

8. Fujihara S, Yokozeki M, Oba Y, Higashibata Y, Nomura S, Moriyama K. Function and regulation of osteopontin in response to mechanical stress. J Bone Miner Res. 2006;21:956-64.

9. Mitsui N, Suzuki N, Maeno M, Mayahara K, Yanagisawa M, Otsuka K, Shimizu $\mathrm{N}$. Optimal compressive force induces bone formation via increasing bone 
sialoprotein and prostaglandin E2 production appropriately. Life Sci. 2005; 77:3168-82.

10. Su M. Expression of connexin 43 in rat mandibular bone and periodontal ligament (PDL) cells during experimental tooth movement. J Dent Res. 1997;76:1357-66.

11. Jiang $L$, Tang Z. Expression and regulation of the ERK $1 / 2$ and p38 MAPK signaling pathways in periodontal tissue remodeling of orthodontic tooth movement. Mol Med Rep. 2017;17:1499-506.

12. Huang L, Meng Y, Ren A, Han X, Bai D, Bao L. Response of cementoblastlike cells to mechanical tensile or compressive stress at physiological levels in vitro. Mol Biol Rep. 2009;36:1741-8.

13. Kim JY, Kim Bl, Jue SS, Park JH, Shin JW. Localization of osteopontin and osterix in periodontal tissue during orthodontic tooth movement in rats. Angle Orthod. 2012;82:107-14.

14. Kahles F, Findeisen HM, Bruemmer D. Osteopontin: a novel regulator at the cross roads of inflammation, obesity and diabetes. Mol Metab. 2014;3:384-93.

15. Wolak T. Osteopontin - a multi-modal marker and mediator in atherosclerotic vascular disease. Atherosclerosis. 2014;236:327-37.

16. Ishii T, Ohshima S, Ishida T, et al. Osteopontin as a positive regulator in the osteoclastogenesis of arthritis. Biochem Biophys Res Commun. 2004;316:809-15.

17. Terai K, Takano-Yamamoto T, Ohba Y, Hiura K, Sugimoto M, Sato M, Kawahata $H$, Inaguma N, Kitamura Y, Nomura S. Role of osteopontin in bone remodeling caused by mechanical stress. J Bone Miner Res. 1999:14:839-49.

18. Morinobu M, Ishijima M, Rittling SR, Tsuji K, Yamamoto H, Nifuji A, Denhardt DT, Noda M. Osteopontin expression in osteoblasts and osteocytes during bone formation under mechanical stress in the calvarial suture in vivo. J Bone Miner Res. 2003;18:1706-15.

19. Jeon YM, Kook SH, Son YO, Kim EM, Park SS, Kim JG, Lee JC. Role of MAPK in mechanical force-induced up-regulation of type I collagen and osteopontin in human gingival fibroblasts. Mol Cell Biochem. 2009;320:45-52.

20. Denhardt DT, Guo X. Osteopontin: a protein with diverse functions. FASEB J. 1993;7:1475-82.

21. Butler WT. The nature and significance of osteopontin. Connect Tissue Res. 1989:23:123-36.

22. McKee MD, Farach-Carson MC, Butler WT, Hauschka PV, Nanci A. Ultrastructural immunolocalization of noncollagenous (osteopontin and osteocalcin) and plasma (albumin and a2HS-glycoprotein) proteins in rat bone. J Bone Miner Res. 1993:8:485-96.

23. McKee MD, Nanci A. Osteopontin and the bone remodeling sequence: colloidal-gold immunocytochemistry of an interfacial extracellular matrix protein. Ann N Y Acad Sci. 1995;760:177-89.

24. Standal T, Borset M, Sundan A. Role of osteopontin in adhesion, migration, cell survival and bone remodeling. Exp Oncol. 2004;26:179-84.

25. Duong LT, Lakkakorpi P, Nakamura I, Rodan GA. Integrins and signaling in osteoclast function. Matrix Biol. 2000;19:97-105.

26. Duong $L T$, Rodan GA. Integrin-mediated signaling in the regulation of osteoclast adhesion and activation. Front Biosci. 1998:3:757-68.

27. Huveneers S, Danen EHJ. Adhesion signaling - crosstalk between integrins, Src and rho. J Cell Sci. 2009:122:1059-69.

28. Zimolo Z, Wesolowski G, Tanaka H, Hyman JL, Hoyer JR, Rodan GA. Soluble alpha $v$ beta 3-integrin ligands raise [Ca2+]i in rat osteoclasts and mousederived osteoclast-like cells. Am J Phys. 1994;266:C376-81.

29. Miyauchi A, Alvarez J, Greenfield EM, et al. Recognition of osteopontin and related peptides by an $\mathrm{a}(\mathrm{v})(\beta 3$ integrin stimulates immediate cell signals in osteoclasts. J Biol Chem. 1991;266:20369-74.

30. Tanabe N, Wheal BD, Kwon J, Chen HH, Shugg RPP, Sims SM, Goldberg HA, Dixon SJ. Osteopontin signals through calcium and nuclear factor of activated T cells (NFAT) in osteoclasts: a novel RGD-dependent pathway promoting cell survival. J Biol Chem. 2011;286:39871-81.

31. Kikuta J, Ishii M. Osteoclast migration, differentiation and function: novel therapeutic targets for rheumatic diseases. Rheumatology. 2013;52:226-34.

32. Negishi-Koga T, Takayanagi H. Ca2+-NFATc1 signaling is an essential axis of osteoclast differentiation. Immunol Rev. 2009;231:241-56.

33. Komarova SV, Pereverzev A, Shum JW, Sims SM, Dixon SJ. Convergent signaling by acidosis and receptor activator of NF-kappaB ligand (RANKL) on the calcium/calcineurin/NFAT pathway in osteoclasts. Proc Natl Acad Sci U S A. 2005;102:2643-8.

34. Ikeda F, Nishimura R, Matsubara T, Hata K, Reddy SV, Yoneda T. Activation of NFAT signal in vivo leads to osteopenia associated with increased osteoclastogenesis and bone-resorbing activity. J Immunol. 2006;177:2384-90
35. Chellaiah MA, Hruska KA. The integrin \{alpha\} \{ $\{\text { beta\} }\}_{3}$ and CD44 regulate the actions of osteopontin on osteoclast motility. Calcif Tissue Int. 2003;72:197-205.

36. Chellaiah MA. Osteopontin deficiency produces osteoclast dysfunction due to reduced CD44 surface expression. Mol Biol Cell. 2003;14:173-89.

37. Rangaswami H, Bulbule A, Kundu GC. Osteopontin: role in cell signaling and cancer progression. Trends Cell Biol. 2006;16:79-87.

38. Zohar R, Suzuki N, Suzuki K, Arora P, Glogauer M, Mcculloch CAG, Sodek J. Intracellular osteopontin is an integral component of the CD44-ERM complex involved in cell migration. J Cell Physiol. 2000;184:118-30.

39. Sugatani T, Alvarez U, Hruska KA. PTEN regulates RANKL- and osteopontinstimulated signal transduction during osteoclast differentiation and cell motility. J Biol Chem. 2003;278:5001-8.

40. Sapir-Koren R, Livshits G. Bone mineralization and regulation of phosphate homeostasis. IBMS Bonekey. 2011;8:286-300.

41. Rodriquez DE, Thula-Mata T, Toro EJ, Yeh YW, Holt C, Holliday LS, Gower LB. Multifunctional role of osteopontin in directing intrafibrillar mineralization of collagen and activation of osteoclasts. Acta Biomater. 2014;10:494-507.

42. Foster BL, Ao M, Salmon CR, et al. Osteopontin regulates dentin and alveolar bone development and mineralization. Bone. 2018;107:196-207.

43. Chung CJ, Soma K, Rittling SR, Denhardt DT, Hayata T, Nakashima K, Ezura Y, Noda M. OPN deficiency suppresses appearance of odontoclastic cells and resorption of the tooth root induced by experimental force application. J Cell Physiol. 2008:214:614-20.

44. Walker CG, Dangaria S, Ito Y, Luan X, Diekwisch TGH. Osteopontin is required for unloading-induced osteoclast recruitment and modulation of RANKL expression during tooth drift-associated bone remodeling, but not for super-eruption. Bone. 2010;47:1020-9.

45. Kuroda S, Balam TA, Sakai Y, Tamamura N, Takano-Yamamoto T. Expression of osteopontin mRNA in odontoclasts revealed by in situ hybridization during experimental tooth movement in mice. J Bone Miner Metab. 2005; 23:110-3.

46. Takano-Yamamoto T, Takemura T, Kitamura Y, Nomura S. Site-specific expression of mRNAs for osteonectin, osteocalcin, and osteopontin revealed by in situ hybridization in rat periodontal ligament during physiological tooth movement. J Histochem Cytochem. 1994;42:885-96.

47. Hong SY, Jeon YM, Lee HJ, Kim JG, Baek JA, Lee JC. Activation of Rho A and FAK induces ERK-mediated osteopontin expression in mechanical forcesubjected periodontal ligament fibroblasts. Mol Cell Biochem. 2010:335:263-72.

48. Boyce BF, Xing L. The RANKL/RANK/OPG pathway. Curr Osteoporos Rep. 2007:5:98-104.

49. Udagawa N, Takahashi N, Jimi E, et al. Osteoblasts/stromal cells stimulate osteoclast activation through expression of osteoclast differentiation factor/ RANKL but not macrophage colony-stimulating factor. Bone. 1999;25:517-23.

50. Han P, Ivanovski S, Crawford R, Xiao Y. Activation of the canonical Wnt signaling pathway induces cementum regeneration. J Bone Miner Res. 2015; 30:1160-74.

51. Lim WH, Liu B, Cheng D, Williams BO, Mah SJ, Helms JA. Wnt signaling regulates homeostasis of the periodontal ligament. J Periodontal Res. 2014; 49:751-9.

52. Lim WH, Liu B, Mah S, Yin X, Helms JA. Alveolar bone turnover and periodontal ligament width are controlled by Wnt. J Periodontol. 2015; 86:319-26.

53. Holguin N, Brodt MD, Silva MJ. Activation of Wnt signaling by mechanical loading is impaired in the bone of old mice. J Bone Miner Res. 2016:31:2215-26.

54. Tu X, Rhee Y, Condon KW, et al. Sost downregulation and local Wnt signaling are required for the osteogenic response to mechanical loading. Bone. 2012;50:209-17.

55. Jimenez-Pellegrin C, Arana-Chavez VE. Root resorption repair in mandibular first premolars after rotation. A transmission electron microscopy analysis combined with immunolabeling of osteopontin. Am J Orthod Dentofac Orthop. 2007;132:230-6.

56. Mizuno N, Shiba H, Mouri Y, Xu W, Kudoh S, Kawaguchi H, Kurihara $H$. Characterization of epithelial cells derived from periodontal ligament by gene expression patterns of bone-related and enamel proteins. Cell Biol Int. 2005;29:111-7.

57. Hasegawa N, Kawaguchi H, Ogawa T, Uchida T, Kurihara H. Immunohistochemical characteristics of epithelial cell rests of Malassez during cementum repair. J Periodontal Res. 2003;38:51-6.

58. Iglesias-Linares A, Yañez-Vico RM, Moreno-Fernández AM, MendozaMendoza A, Orce-Romero A, Solano-Reina E. Osteopontin gene SNPS 
(rs9138, rs1 1730582) mediate susceptibility to external root resorption in orthodontic patients. Oral Dis. 2014;20:307-12.

59. Iglesias-Linares A, Sonnenberg B, Solano B, Yañez-Vico RM, Solano E, Lindauer SJ, Flores-Mir C. Orthodontically induced external apical root resorption in patients treated with fixed appliances vs removable aligners. Angle Orthod. 2017:87:3-10.

60. Borilova Linhartova P, Cernochova P, Kastovsky J, Vrankova Z, Sirotkova M, Izakovicova Holla L. Genetic determinants and postorthodontic external apical root resorption in Czech children. Oral Dis. 2017;23:29-35.

61. Castroflorio T, Gamerro EF, Caviglia GP, Deregibus A. Biochemical markers of bone metabolism during early orthodontic tooth movement with aligners. Angle Orthod. 2017;87:74-81

62. Barbieri G, Solano P, Alarcón JA, Vernal R, Rios-Lugo J, Sanz M, Martín C Biochemical markers of bone metabolism in gingival crevicular fluid during early orthodontic tooth movement. Angle Orthod. 2013;83:63-9.

63. George A, Evans CA. Detection of root resorption using dentin and bone markers. Orthod Craniofacial Res. 2009:12:229-35.

64. Kido J, Nakamura T, Asahara Y, Sawa T, Kohri K, Nagata T. Osteopontin in gingival crevicular fluid. J Periodontal Res. 2001;36:328-33.

65. Smuthkochorn S, Palomo JM, Hans MG, Jones CS, Palomo L. Gingival crevicular fluid bone turnover biomarkers: how postmenopausal women respond to orthodontic activation. Am J Orthod Dentofac Orthop. 2017:152:33-7.

66. Singh A, Gill G, Jakhu H, Gill G. Epigenetics and its implications for oral health. J Oral Biosci. 2018; https://doi.org/10.1016/j.job.2018.02.001.

67. Baloul SS, Gerstenfeld LC, Morgan EF, Carvalho RS, Van Dyke TE, Kantarci A Mechanism of action and morphologic changes in the alveolar bone in response to selective alveolar decortication-facilitated tooth movement. Am J Orthod Dentofac Orthop. 2011;139:583-101.

68. Harada H, Tagashira S, Fujiwara M, Ogawa S, Katsumata T, Yamaguchi A, Komori T, Nakatsuka M. Cbfa1 isoforms exert functional differences in osteoblast differentiation. J Biol Chem. 1999;274:6972-8.

69. Fatherazi S, Matsa-Dunn D, Foster BL, Rutherford RB, Somerman MJ, Presland RB. Phosphate regulates osteopontin gene transcription. J Dent Res. 2009;88:39-44

70. Pike JW, Lee SM, Meyer MB. Regulation of gene expression by 1,25 dihydroxyvitamin D3 in bone cells: exploiting new approaches and defining new mechanisms. Bonekey Rep; 2014. https://doi.org/10.1038/bonekey.2013.216.

\section{Submit your manuscript to a SpringerOpen ${ }^{\circ}$ journal and benefit from:}

- Convenient online submission

- Rigorous peer review

- Open access: articles freely available online

- High visibility within the field

- Retaining the copyright to your article 